\title{
MICROWAVE PERMITTIVITY AND PERMEABILITY PROPERTIES AND MICROWAVE REFLECTIONS OF FERRITE POWDERS
}

\author{
Mohammed N. Afsar, Ana Medina Ayala, Nawaf Al-Moayed, and Mahmut Obol \\ High Frequency Materials Measurement and Information Center, Department of Electrical and Computer \\ Engineering, Tufts University, Medford, MA
}

\begin{abstract}
$\underline{\text { Abstract }}$
Magnetic powders applications are becoming attractive in electromagnetic shielding interferences in wireless systems. Magnetic powders are also very important in magnetic resonances imaging and as well as the drug delivery applications in biomedical research. As such, a good understanding of the magnetic powders' microwave responses is crucial in modern technological applications. In this paper we present accurate broad-band data on the real and imaginary parts of permeability and permittivity of $\mathrm{Ni}_{1-\mathrm{x}-\mathrm{y}} \mathrm{Co}_{\mathrm{x}} \mathrm{Cu}_{\mathrm{y}} \mathrm{Fe}_{2-\mathrm{z}-\mathrm{d}} \mathrm{Mn}_{\mathrm{z}} \mathrm{O}_{4}$ and $\mathrm{Ni}_{1-\mathrm{x}} \mathrm{Zn}_{\mathrm{x}} \mathrm{Fe}_{2-\mathrm{y}} \mathrm{Mn}_{\mathrm{y}} \mathrm{O}_{4}$ substrates in the frequency range of 4 to $40 \mathrm{GHz}$.
\end{abstract}

\section{Introduction}

The objective of this work is to present the magnetic characteristics of two ferrite composite materials. These two commercially available magnetic components, purchased from Trans-Tech, are labeled as TT2-111 and TT86-6000. To carry out the measurements, the samples, whose complex permittivity and permeability will be determined, are placed in the test ports and measured with a network analyzer. Calibration standards are measured at the same test ports for different frequency bands. The method applied for the calibration is the TRL (through-reflect-line) full 2 port calibration. The calibrated parameters help determine the complex permeability and permittivity of the samples.

\section{$\underline{\text { Experiment }}$}

The precision permeability and permittivity measurements of various materials were reported in former researches [1], [2], [3], [4] and [5]. In this work, two Nickel Zinc Spinel Ferrites powders $\left(\mathrm{Ni}_{1-\mathrm{x}}\right.$ ${ }_{\mathrm{y}} \mathrm{Co}_{\mathrm{x}} \mathrm{Cu}_{\mathrm{y}} \mathrm{Fe}_{2-\mathrm{z}-\mathrm{d}} \mathrm{Mn}_{\mathrm{z}} \mathrm{O}_{4}$ and $\mathrm{Ni}_{1-\mathrm{x}} \mathrm{Zn}_{\mathrm{x}} \mathrm{Fe}_{2-\mathrm{y}} \mathrm{Mn}_{\mathrm{y}} \mathrm{O}_{4}$ ) were loaded in the waveguides of six different angular waveguides, $\mathrm{G}$ (4 to $6 \mathrm{GHz}$ ), $\mathrm{C}$ ( 4 to $8 \mathrm{GHz}$ ), $\mathrm{X}$ ( 8 to $12.4 \mathrm{GHz}), \mathrm{Ku}$ (12.4 to $18 \mathrm{GHz}$ ), $\mathrm{K}$ (18 to $26.5 \mathrm{GHz}$ ) and $\mathrm{Ka}$ bands (26.5 to $40 \mathrm{GHz}$ ). We use Vector Network Analyzer (VNA) to get the data and perform transmission and reflection measurements on the samples. The modified NRW method, used in a previous paper [1], is used to obtain the permeability and permittivity of the samples (equations 1 and 2) and the Jarvis-Baker method [3] is used to calculate the scattered parameters $\left(S_{11}\right.$ and $\left.S_{21}\right)$ for free space measurements.

$$
\begin{aligned}
& \mu=\frac{\eta \gamma_{T E_{10}}}{j \gamma_{T E_{10}}^{0}}=-j\left(\frac{1+\Gamma}{1-\Gamma}\right)\left(\frac{1}{2 \pi d}\right)\left(\frac{\ln \left(\frac{1}{|T|}\right)+j\left(2 \pi n-\varphi_{T}\right)}{\sqrt{\left(\frac{1}{\lambda_{0}}\right)^{2}-\left(\frac{1}{2 a}\right)^{2}}}\right) \\
& \varepsilon=-j\left(\frac{c}{f}\right)^{2}\left(\frac{1-\Gamma}{1+\Gamma}\right)\left(\frac{1}{2 \pi d}\right)\left(\ln \left(\frac{1}{\mid T T}\right)+j\left(2 \pi n-\varphi_{T}\right)\right)\left(\sqrt{\left(\frac{1}{\lambda_{0}}\right)^{2}-\left(\frac{1}{2 a}\right)^{2}}\right)
\end{aligned}
$$

Data is obtained by performing measurements at 201 equally spaced frequency points. The data is stored, and the scattered complex permittivity and permeability of the composite materials are calculated from the measured s-parameters using a Matlab program based on the Weir algorithm [2].

\section{$\underline{\text { Results }}$}

Figures 1 and 2 represent the real and imaginary parts of the permittivity and permeability of the two substrates.

$\mathbf{N i}_{1-x-y} \mathrm{Co}_{\mathbf{x}} \mathrm{Cu}_{\mathbf{y}} \mathrm{Fe}_{2-\mathrm{z}-\mathrm{d}} \mathrm{Mn}_{\mathrm{z}} \mathrm{O}_{4}$ : The real permeability presents a peak at the $\mathrm{Ka}$ band, reaching the maximum value at $40 \mathrm{GHz}$ with a value of 1.19 , but in general it has a flat response. The imaginary permeability presents a dip in the $\mathrm{K}$ band from 0.09 to 0.02 . In this band the highest peak is located in the lowest spectrum band. This is due to the Cobalt present in the sample, which helps to reduce the anisotropy. The response of the real permittivity remains almost the same at different frequency values. The lowest value (2.22) is located at the $\mathrm{K}$ band and the highest peak (2.31) is at lower frequencies at the $\mathrm{G}$ band. The imaginary permittivity has a maximum value of 0.35 at the $G$ band and then it decreases gradually until it starts to rise again slowly at the Ka band.

$\mathbf{N i}_{1-\mathrm{x}} \mathbf{Z n}_{\mathbf{x}} \mathbf{F e}_{2-\mathrm{y}} \mathbf{M n}_{\mathbf{y}} \mathbf{O}_{4}$ : From Figure 2, it can be seen that the highest value of the real permeability is at the $\mathrm{Ka}$ band, having a value of 1.2 at the maximum frequency of the spectrum. In the $\mathrm{K}$ band, the imaginary permeability presents a high peak at 25.7 
$\mathrm{GHz}$ reaching a value of 0.0197. At lower frequencies the value of the imaginary permeability is very small and while the frequency gets higher (Ka band), it is almost zero. The highest values of the real permittivity (2.32-2.33) are located at the $\mathrm{Ku}$ band. The lowest values correspond to frequencies at the $\mathrm{Ka}$ band. For the imaginary permittivity, the highest values are the response to low frequencies ( $\mathrm{G}$ band). The highest value is 0.64 . This response decreases progressively reaching small values that can be approximated to zero (at the $\mathrm{K}$ band). Then, it presents a low increment at the Ka band

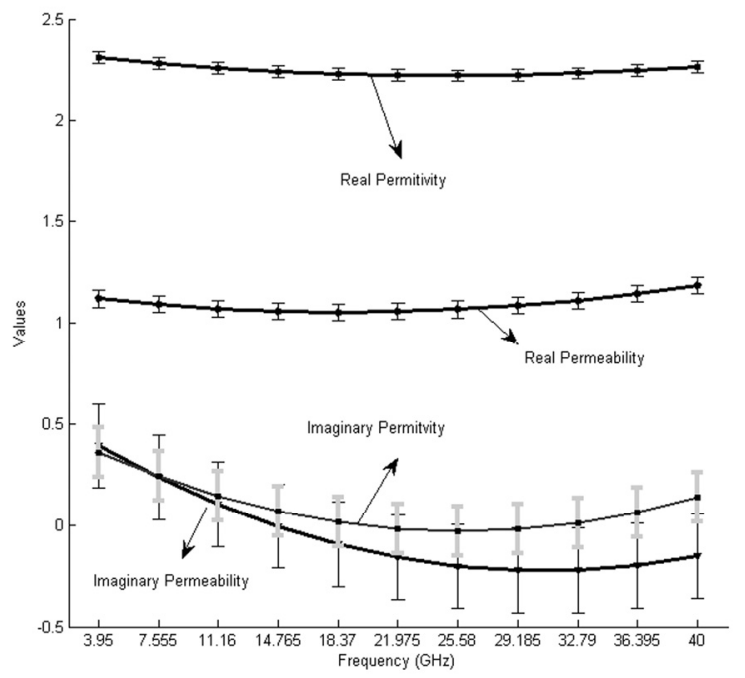

Figure 1: Complex permeability and permittivity of $\mathrm{Ni}_{1-\mathrm{x}-\mathrm{y}} \mathrm{Co}_{\mathrm{x}} \mathrm{Cu}_{\mathrm{y}} \mathrm{Fe}_{2-\mathrm{z}-\mathrm{d}} \mathrm{Mn}_{\mathrm{z}} \mathrm{O}_{4}$ (TT2-111) as a function of the frequency.

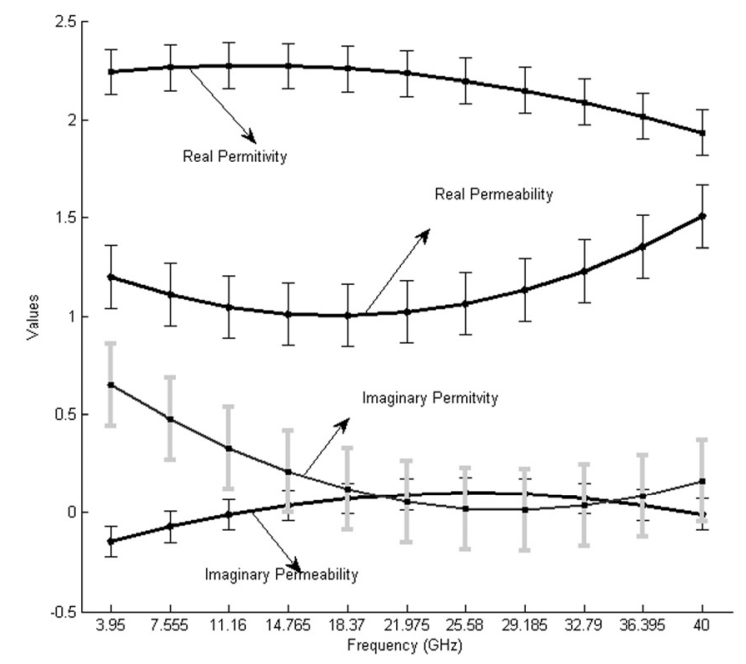

Figure 2: Complex permeability and permittivity of $\mathrm{Ni}_{1-\mathrm{x}} \mathrm{Zn}_{\mathrm{x}} \mathrm{Fe}_{2-\mathrm{y}} \mathrm{Mn}_{\mathrm{y}} \mathrm{O}_{4}$ (TT86-6000) as a function of the frequency.

\section{$\underline{\text { Discussion and conclusions }}$}

The complex permittivity and permittivity of two important ferrite powders were determined in a very precise manner. The obtained results are reasonable, the measured permittivity and permeability depend on the density of magnetic particles, size of magnetic particles, and the volume fraction matter of magnetic particles. For permittivity measurements we have not seen any difference between TT2 and TT86. However, taking the permeability measurements, the TT2 seems to present more magnetic lost than the TT86 at lower frequencies. This might be reasonable due to cobalt content normally induce higher internal anisotropy fields in ferrites. Calculating the reflection $\left(\mathrm{S}_{11}\right)$ of both powders, it has been shown that the powders generate more reflectivity at higher frequencies than in lower frequencies band. This is consistent what we have obtained in the real measurements of $S_{11}$ and $S_{21}$ measurements. We will present this part in extended paper.

This research is supported by a contract from US Army National Ground and Intelligence Center

\section{$\underline{\text { References }}$}

Nawaf N. Al-Moayed, Mohammed N. Afsar, Usman A. Khan, Sean McCooey, Mahmut Obol, " Nano Ferrites Microwave Complex Permeability and Permittivity Measurements by T/R Technique in Waveguide", June 19 2007 manuscript was received to be published in IEEE, Transactions on Magnetics.

[2] W. B. Weir, "Automatic measurement of complex dielectric constant and permeability at microwave frequencies," Proceedings of the IEEE,vol. 62, No.1, pp. 33-36, January 1974.

[3] J. Baker-Jarvis, E. J. Venzura, and W. A. Kissick, "Improved technique for determining complex permittivity with the transmission/reflection method," IEEE Trans. Microwave Theory Tech., vol. 38, No.8, pp. 1096-1103, August 1990.

[4] Rene Grignon, Mohammed N. Afsar, Yong Wang and Saquib, Butt, "Microwave broadband free-space complex dielectric permittivity measurements on low loss solids," IMTC 2003-Instrumentation and Measurement Technology Conference, Vail CO, USA, 20-22 May 2003.

[5] Adil Bahadoor, Yong Wang, and Mohammed N. Afsar, "Complex permittivity and permeability of barium and strontium ferrite powders in $X, K U$, and $K$-band frequency ranges", JOURNAL OF APPLIED PHYSICS 97, 10F105, 2005. 